\title{
Respostas fisiológicas e desempenho produtivo de ovinos em pasto suplementados com diferentes fontes proteicas ${ }^{1}$
}

\author{
Pablo Teixeira Leal de Oliveira², Silvia Helena Nogueira Turco³, Tadeu Vinhas Voltolini', \\ Gherman Garcia Leal de Araújo ${ }^{4}$, Luiz Gustavo Ribeiro Pereira ${ }^{5}$, Claudio Mistura ${ }^{6}$ Daniel Ribeiro Menezes 7
}

\section{RESUMO}

Objetivou-se avaliar a influência dos fatores climáticos sobre o desempenho produtivo e as respostas fisiológicas de ovinos submetidos a diferentes suplementos proteicos em pastagem de capim-Tifton 85 (Cynodon spp.) irrigado nas condições climáticas do semiárido brasileiro. Utilizaram-se 28 ovinos, machos, castrados, mestiços Santa Inês x SPRD (sem padrão racial definido), com peso inicial de $28 \mathrm{~kg}$, recebendo três diferentes fontes de proteína no suplemento (farelo de soja, torta de algodão e ureia) e um tratamento testemunha (pastagem exclusiva). Foram determinados o consumo de matéria seca, ganho em peso, os parâmetros fisiológicos - frequência respiratória (FR), temperaturas superficial (TS) e retal (TR) - dos animais e os parâmetros ambientais. Nas condições climáticas impostas pelo experimento, o turno da tarde conduziu os animais, independentemente da dieta, a uma condição de elevado estresse pelo calor. A suplementação influenciou o consumo de matéria seca de forragem sem alterar o desempenho dos ovinos, sendo economicamente inviável. A fonte proteica obtida a partir da torta de algodão e utilizada no suplemento para ovinos em pastejo elevou a FR, influenciando sobre seu conforto térmico.

Palavras-chave: Cynodon spp., semiárido, estresse, pastagem irrigada, suplementação.

\section{ABSTRACT}

\section{Physiological responses and performance of sheep on pasture supplemented with different protein sources}

This study was carried out to evaluate the influence of climatic factors on performance and physiological responses of sheep fed on different protein supplements in grazing Tifton 85 (Cynodon spp.) irrigated in conditions of Brazilian semiarid climate. A total of 28 male Santa Ines x SPRD (undefined breed), castrated lambs, with initial weight of $28 \mathrm{~kg}$, received three different sources of protein in the supplement (soybean meal, cotton cake and urea) and a control treatment, only on grass. The parameters evaluated were: dry matter intake, average daily gain, physiological parameters [respiratory rate (FR), surface temperature (TS) and rectal temperature (TR)] and environmental parameters. Under the climatic conditions imposed by the experiment, the period of the afternoon led the animals to a condition of high heat stress, regardless of the diet. Supplementation affected roughage intake without changing sheep performance, making it economically unfeasible. Protein source derived from cotton cake and used in the supplement for the lambs in grazing increased FR, influencing their thermal comfort.

Key words: Cynodon spp., semiarid, stress, irrigated pasture, supplementation.

Recebido para publicação em novembro de 2009 e aprovado em março de 2011

'Pesquisa financiada pelo Ministério da Integração Nacional (MIN) e pelo Banco Interamericano de Desenvolvimento (BID).

${ }^{2}$ Engenheiro-Agrônomo, Mestre. Instituto Federal de Educação, Ciência e Tecnologia do Sertão Pernambucano, BR 235, KM 22, Senador Nilo Coelho, número 4, 56300-000, Petrolina, Pernambuco, Brasil. pabloleal4@ hotmail.com

${ }^{3}$ Engenheira-Agrícola, Doutora. Universidade Federal do Vale do São Francisco, Colegiado de Engenharia Agrícola, Avenida Antônio Carlos Magalhães, 510, Country Club, 48902300, Juazeiro, Bahia, Brasil. Silvia.turco@univasf.edu.br

${ }^{4}$ Zootecnistas, Doutores. Embrapa Semi-Árido. BR 428, Km 152, Zona Rural, Caixa Postal 23, 56302-970, Recife, Pernambuco, Brasil. tadeu.voltolini@cpatsa.embrapa.br; ggla@cpatsa.embrapa.br

${ }^{5}$ Médico Veterinário, Doutor. Embrapa Semi-Árido. BR 428, Km 152, Zona Rural, Caixa Postal 23, 56302-970, Recife, Pernambuco, Brasil. luiz.gustavo@cpatsa.embrapa.br ${ }^{6}$ Engenheiro-Agrônomo, Doutor. Universidade do Estado da Bahia, DTCS, Campos III, Avenida Edgard Chastinet, 0, - São Geraldo, 48905-650, Juazeiro, Bahia, Brasil cmistura@hotmail.com

7 Médico Veterinário, Mestre. Universidade Federal do Vale do São Francisco, Avenida José de Sá Maniçoba, s/n, Centro, 56330-480, Petrolina, Pernambuco, Brasil. daniel.menezes@univasf.edu.br 


\section{INTRODUÇÃO}

A criação brasileira de ovinos destinada à produção de carne tem expandido na última década. Segundo dados do censo agropecuário no Brasil (IBGE, 2009), o efetivo de caprinos e de ovinos estimado para 2007 foi de 9,4 e 16,2 milhões de cabeças, respectivamente; desses, 8,6 milhões de caprinos e 9,3 milhões de ovinos estão na região Nordeste. Esses pequenos ruminantes, na sua grande maioria, são formados por animais Sem Padrão Racial Definido (SPRD), de notável rusticidade, porém com baixa produtividade, criados em sistema de exploração extensivo na caatinga, resultando em baixos índices de desempenho produtivo (Andrade et al., 2007; Moreira et al., 2008; Voltolini et al., 2009).

A utilização das estratégias alimentares de suplementação e de pastagens irrigadas adaptadas à região é de fundamental importância, já que permite regularizar a oferta de alimento, principalmente em período de estiagens prolongadas. Além do mais, essas pastagens podem assegurar valor nutritivo superior, quando pastejada ou conservada no estádio fenológico ideal. O uso de pastagens irrigadas é considerado excelente opção tecnológica na região semiárida, devido à disponibilidade de fatores abióticos, a exemplo das elevadas temperaturas e luminosidade, fatores esses que conferem maior eficiência de resposta das gramíneas tropicais aos insumos aplicados (Fagundes et al., 2005).

Por outro lado, a elevada temperatura e radiação presente no semiárido brasileiro também apresentam grande influência sobre o conforto térmico desses pequenos ruminantes, principalmente quando criados em sistemas totalmente expostos aos fatores ambientais. Assim, animais estressados apresentam alterações no seu comportamento e bem-estar, que resultam em declínios no consumo e na digestão dos alimentos (Neiva et al., 2004; Verissimo, et al., 2009), podendo afetar negativamente o desempenho animal (Starling et al., 2002; Neiva et al., 2004).

Além das condições climáticas, a ingestão alimentar em ruminantes também é afetada pelos tipos de alimentos. Esses efeitos podem interferir na resposta do potencial genético dos animais.

Esta pesquisa objetivou avaliar a influência dos fatores climáticos sobre o desempenho produtivo e as respostas fisiológicas de ovinos submetidos a diferentes suplementos proteicos em pastagem de capim-Tifton 85 (Cynodon spp.) irrigado nas condições climáticas do semiárido brasileiro, no sertão de Pernambuco.

\section{MATERIAL E MÉTODOS}

O ensaio experimental foi conduzido na Embrapa Semiárido, no sistema de produção de ovinos em pastagem irrigada do campo experimental Bebedouro, localiza- do no município de Petrolina-PE. Segundo a classificação climática de Köppen, a região apresenta clima do tipo BSWh', semiárido, e valores médios anuais das variáveis climatológicas: temperatura do $\operatorname{ar}=26,5^{\circ} \mathrm{C}$, precipitação pluvial $=541,1 \mathrm{~mm}$, umidade relativa do ar $=65,9 \%$ e velocidade do vento $=2,3 \mathrm{~m} / \mathrm{s}$. A precipitação é irregularmente distribuída no espaço e no tempo, concentrando-se de dezembro a abril, e a insolação anual é superior a $3.000 \mathrm{~h}$ (Campos et al., 2008).

Foram avaliados 28 ovinos, machos, castrados, mestiços Santa Inês x SPRD (sem padrão racial definido), com peso vivo médio de $28 \pm 2 \mathrm{~kg}$ e distribuídos em taxa de lotação variando conforme a disponibilidade de forragem e para assegurar a oferta de $10 \%$ do peso vivo. Os animais foram vermifugados 15 dias antes de ingressarem na área experimental e durante todo período experimental após a prévia análise da pigmentação da mucosa ocular, utilizando o cartão Famacha® (Molento et al., 2004).

Os tratamentos constituíram de três suplementos com diferentes fontes proteicas: torta de algodão (TA), farelo de soja (FS), ureia (UR) e pastagem exclusiva (PA) como testemunha. Os animais eram divididos em baias por tratamento, sendo o suplemento ofertado em proporções iguais a $180 \mathrm{~g}$ de MS/dia, pela manhã, distribuídos em cochos coletivos medindo $0,7 \mathrm{~m}$ /animal. Os animais do tratamento com pastagem exclusiva eram mantidos em uma baia sem suplementação durante o período em que os ovinos suplementados consumiam as dietas.

Os suplementos foram formulados para atingir teores de $20 \%$ de proteína bruta e $73,8 \%$ de nutrientes digestíveis totais, conforme National Research Council (NRC, 2007). Os ingredientes utilizados, suas proporções e a composição química podem ser observados na Tabela 1.

Para a manutenção do suporte forrageiro foi adotado o sistema de pastejo com taxa de lotação intermitente no capim-Tifton 85 (Cynodon spp.) irrigado com sistema em malha por aspersão convencional com canhão. A área de 0,5 hectare de pastagem foi dividida em 24 piquetes de $208,33 \mathrm{~m}^{2}$ cada. O ciclo de pastejo foi definido em 24 dias, sendo um dia de ocupação e 23 dias de descanso, no qual os animais de todos os tratamentos eram mantidos juntos num mesmo piquete. Aárea foi adubada com fósforo (200 $\mathrm{kg}$ de superfosfato simples) e potássio (100 kg de cloreto de potássio) de acordo com a análise de solo e interpretação pelo Laboratório de Analise de Solos da Embrapa Semiárido. A adubação nitrogenada foi realizada com a aplicação de $500 \mathrm{~kg}$ de nitrogênio/ha/ano aplicada a lanço, após a saída dos animais em cada piquete na forma de ureia.

A massa de forragem em pré e pós-pastejo foi estimada por meio de coletas de amostras, utilizando-se moldura em formato quadrado $\left(0,25 \mathrm{~m}^{2}\right)$. Foram coletadas duas amostras aleatórias em pré e pós-pastejo de cada um dos 
três piquetes pastejados, em cada subperíodo, sempre cortadas rente ao solo.

A massa de folhas, os colmos e o material morto foram determinados a partir da separação e quantificação do peso seco de cada um dos componentes a partir de subamostras de massa de forragem (aproximadamente $100 \mathrm{~g}$ ) tanto no pré quanto no pós-pastejo. As amostras de planta inteira, folhas, colmos e material morto, assim como os demais componentes, foram pesados in natura e levados à estufa de circulação forçada de ar e mantidas por $48 \mathrm{~h}$ a $55{ }^{\circ} \mathrm{C}$ para a quantificação do seu peso seco.

A altura do dossel foi estimada pelo comprimento, desde o nível do solo até a curvatura de uma das folhas completamente expandidas, utilizando-se uma régua de madeira de $0,50 \mathrm{~m}$ de comprimento, graduada em centímetros. Foram tomadas 20 medidas por piquete durante o período de coleta para o pré e o pós-pastejo.

As análises para determinação dos teores de proteína bruta, da fibra em detergente neutro e digestibilidade in vitro da matéria seca foram realizadas de acordo com Silva e Queiroz (2002).

Na Tabela 2, estão apresentados os valores de caracterização qualitativa e quantitativa da pastagem de Tifton 85 utilizada no presente estudo.

Para a obtenção dos dados da caracterização do ambiente térmico foi instalado na área experimental, no centro de um dos 24 piquetes, um abrigo meteorológico contendo termoigrômetro, termômetro de globo negro e anemômetro digital, em que foi obtida a leitura da temperatura de bulbos seco e úmido, temperatura de globo negro e velocidade do vento. Estes dados foram coletados a cada três dias, de hora em hora, necessários para obtenção da temperatura do ar (Tar), umidade relativa (UR) e do índice de temperatura de globo e umidade (ITGU). As va- riáveis climáticas foram avaliadas pela análise de variância ( $\mathrm{P}<0,05)$ e, quando significativas, procedeu-se a análise de regressão polinomial utilizando o software WinStat (Machado \& Conceição, 2002).

A determinação da eficiência térmica pelo índice de temperatura de globo negro e umidade (ITGU), conforme Buffington et al. (1981), foi obtida pela equação: ITGU = 0,72 $(\mathrm{Tg}+\mathrm{Tbu})+40,6$, em que: $\mathrm{Tg}=$ temperatura do termômetro de globo negro $\left({ }^{\circ} \mathrm{C}\right)$ e Tbu $=$ temperatura de termômetro de bulbo úmido $\left({ }^{\circ} \mathrm{C}\right)$. As avaliações da frequência respiratória (FR), temperatura superficial (TS) e temperatura retal (TR) foram realizadas a campo, a cada duas horas, com cinco horários pré-estabelecidos (9:00; 11:00; 13:00; 15:00; e 17:00 horas), a cada 14 dias, durante todo período experimental de 84 dias entre junho a setembro de 2007. Nessas avaliações foi utilizado o delineamento inteiramente casualizado em arranjo fatorial 4 x 5 (quatro fontes proteicas no suplemento $\mathrm{x}$ cinco horários), com quatro repetições.

Para a determinação da TS, utilizou-se o termômetro laser infravermelho IP-550, Impac $\AA$, com precisão de \pm 2 ${ }^{\circ} \mathrm{C}$, a uma distância de $10 \mathrm{~cm}$, na pele em três locais distintos (pescoço, caixa torácica e flanco), que originaram a média. Enquanto para a TR, utilizou-se um termômetro clínico veterinário INCOTERM ${ }^{\circledR}$, com escala de $34{ }^{\circ} \mathrm{C}$ a $44{ }^{\circ} \mathrm{C}$, introduzido a $10 \mathrm{~cm}$ no reto de cada animal por dois minutos. Já a FR, quantificada em número de respirações por minuto, foi obtida pela contagem da movimentação do flanco dos ovinos durante 15 segundos e multiplicando por quatro, obtendo-se a frequência por minuto.

A pesagem dos animais foi realizada a cada 14 dias, no início da manhã, antes de ofertar o suplemento. Para estimar o consumo de matéria seca foi realizada coleta total de fezes em quatro ovinos por tratamento, mantendo os

Tabela 1. Proporção dos ingredientes e composição nutricional dos suplementos

\begin{tabular}{lccc}
\hline \multirow{2}{*}{ Ingredientes } & \multicolumn{3}{c}{ Suplementos Proteicos (\% da MS) } \\
\cline { 2 - 4 } & Farelo de soja & Ureia & Torta de algodão \\
\hline Milho grão moído fino & 50,0 & 84,0 & 55,0 \\
Farelo de trigo & 20,0 & 10,0 & 5,0 \\
Farelo de soja & 28,0 & - & - \\
Ureia & - & 4,0 & - \\
Torta de algodão & - & - & 38,0 \\
Suplemento mineral e vitamínico & 1,0 & 1,0 & 1,0 \\
Calcário calcítico & 1,0 & 1,0 & 1,0 \\
\hline & Composição Nutricional & 90,03 \\
\hline MS & 90,95 & 69,78 & 7,94 \\
M M & 5,96 & 6,46 & 92,06 \\
MO & 94,04 & 93,54 & 25,43 \\
PB, \% da MS & 27,81 & 34,18 & 74,52 \\
DIVMS & 84,12 & 81,17 & 24,77 \\
FDN & 27,69 & 23,27 & 10,13 \\
FDA & 6,77 & 4,45 & \\
\hline
\end{tabular}


Tabela 2. Caracterização qualitativa e quantitativa da pastagem de Tifton 85 (Cynodon dactylon) patejado pelos ovinos

\begin{tabular}{lcc}
\hline Componentes & Média & Desvio-padrão \\
\hline Altura do dossel pré-pastejo, cm & 16,52 & 4,84 \\
Altura do dossel pós-pastejo, cm & 11,86 & 3,42 \\
Massa de forragem pré-pastejo, kg de MS/ha & 1.397 & 567 \\
Massa de forragem pós-pastejo, kg de MS/ha & 1.056 & 375 \\
Massa de folhas pré-pastejo, kg de MS/ha & 452 & 146 \\
Massa de colmos pré-pastejo, kg de MS/ha & 689 & 249 \\
Massa de folhas pós-pastejo, kg de MS/ha & 188 & 127 \\
Massa de colmos pós-pastejo, kg de MS/ha & 650 & 131 \\
Proteína bruta pré-pastejo, \% da MS & 10,86 & 3,13 \\
Fibra em detergente neutro pré-pastejo, \% da MS & 73,74 & 8,39 \\
Digestibilidade in vitro da MS pré-pastejo, \% da MS & 48,35 & 5,30 \\
\hline
\end{tabular}

mesmos animais nos subperíodos e utilizando-se uma bolsa acoplada neles. As coletas foram realizadas durante três dias consecutivos, em intervalos de aproximadamente 30 dias (quatro subperíodos). O conteúdo da bolsa foi coletado duas vezes ao dia, às 8 e às 14 h, sendo pesado, amostrado e congelado a $-10{ }^{\circ} \mathrm{C}$.

O consumo de matéria seca (CMS) dos animais mantidos exclusivamente em pastagens foi estimado a partir da equação: CMS total de forragem ( $\mathrm{kg}$ de MS/animal/dia) = PF total/1-DIVMS da forragem, sendo PF = produção fecal e DIVMS = digestibilidade in vitro da matéria seca. $\mathrm{O}$ consumo de matéria seca total dos animais que receberam suplementos foi estimado por meio da soma do CMS de forragem e do CMS de suplemento.

O CMS de suplemento foi estimado subtraindo-se a quantidade de sobras da quantidade de suplemento oferecida. O CMS de forragem foi estimado a partir das equações: CMS de forragem = PF oriunda da forragem $/ 1$ DIVMS da forragem; PF oriunda da forragem $=$ PF total PF oriunda do suplemento; e PF oriunda do suplemento = CMS de suplemento - CMS de suplemento * DIVMS do suplemento (Martinez, 2004).

Para as variáveis de consumo de matéria seca total, suplemento, forragem e ganho em peso foi utilizado o delineamento inteiramente casualizado, com quatro repetições, utilizando-se análise de variância $(\mathrm{P}<0,05)$ e, quando significativo, procedeu-se o teste de média de Tukey ( $\mathrm{P}<0,05)$. Já para frequência respiratória, temperaturas superficial e retal procedeu-se o teste de interação e análise de regressão utilizando o software WinStat (Machado \& Conceição, 2002).

\section{RESULTADOS E DISCUSSÃO}

Os valores meteorológicos de umidade relativa do ar (UR), temperatura do ar (Tar) e índice de temperatura de globo e umidade (ITGU), observados durante o ensaio bioclimatológico, nos horários das 9 às 17 h, encontramse na Figura 1.
No que diz respeito à umidade relativa do ar (UR), observa-se que os valores foram às $9 \mathrm{~h}$ de $50,87 \%$ e às 17 $\mathrm{h}$ de $39,91 \%$, com a mínima ocorrida às $15 \mathrm{~h} 02$ equivalente a $38,58 \%$ estando compatíveis com os estabelecidos como adequados por Baêta \& Souza (1997) de 40 a $70 \%$. Esses resultados estão de acordo com Oliveira et al. (2005), que observaram valores de UR de 59,8 e 38,4\% nos ambientes cobertos com telha de barro e 62,2 e $39,8 \%$ no ambiente coberto com telha de fibrocimento nos períodos da manhã e tarde, respectivamente, também sendo semelhantes aos encontrados por Souza et al. (2005) e Souza et al. (2007) que, em trabalhos no sertão paraibano, descrevem valores médios de 61,0 e $41,0 \%$ de UR e 71,0 e $38,0 \%$ de UR, respectivamente, para os turnos da manhã e tarde.

Ao estimar os valores de Tar ao longo do dia, observa-se que às $9 \mathrm{~h}$ foi de $26,70^{\circ} \mathrm{C}$ e às $17 \mathrm{~h}$ de $35,74^{\circ} \mathrm{C}$, com máxima $\left(\mathrm{X}_{\text {máx. }}\right)$ obtida às $14 \mathrm{~h} 35$, equivalente a $38,67^{\circ} \mathrm{C}$ $\left(\mathrm{Y}_{\text {máx. }}\right)$. Valores estes, quando comparados com os estabelecidos como zona de conforto térmico para ovelhas adultas, que, segundo Baêta \& Souza (1997), fica na faixa de 15 a $30^{\circ} \mathrm{C}$, e a temperatura crítica superior a $35^{\circ} \mathrm{C}$, o que caracteriza uma situação de estresse térmico para es-

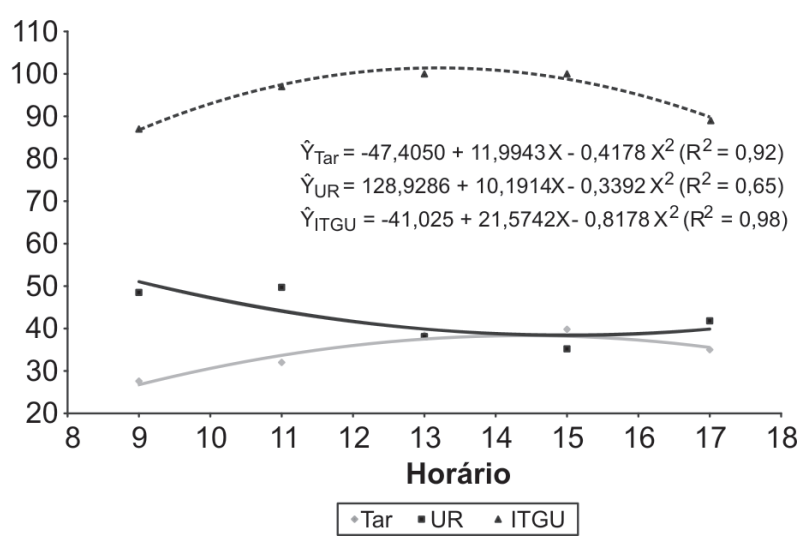

Figura 1. Temperatura do ar (Tar), umidade relativa (UR) e índice de temperatura de globo e umidade (ITGU) das 9 às $17 \mathrm{~h}$. 
sas condições experimentais. Assim, numa análise mais profunda dos valores da presente pesquisa, constata-se que apenas de 9 às $10 \mathrm{~h}$ os animais se mantiveram dentro da faixa de zona de conforto e até às $12 \mathrm{~h}$ abaixo da temperatura crítica superior, enquanto nas no período da tarde (> 12 às $17 \mathrm{~h}$ ) os animais permaneceram em estresse por calor. Esses valores foram semelhantes aos encontrados por Santos et al. (2005) e Souza et al. (2007), ou seja, valores dentro da zona de conforto térmico no período da manhã e desconforto no período da tarde na estação seca do semiárido.

Os valores de ITGU obtidos no presente estudo foram de 86,90 às 9h, 89,39 às 17 h e o máximo ITGU encontrado às 13 h 19 com 101,26. Porém, na literatura inexistem valores de ITGU estimados para ovinos, sendo somente para bovinos de leite. Todavia, numa situação em que o ITGU encontra-se acima de 85 , como os reportados no presente estudo, chamam a atenção. Essa faixa, segundo Baêta \& Souza (1997), é considerada como condição de emergência de estresse térmico para vacas de leite, sendo necessária a adoção de providências urgentes como sombreamento ou resfriamento do ambiente para evitar prejuízos aos animais. Nesse contexto, associando o ITGU a parâmetros de conforto de calor como a FR, constata-se que os ovinos encontravam-se em situação de estresse térmico, já que há a elevação da FR ( P < 0,05), como demonstrado pelas equações de modelo quadrático ajustadas para de 9 às $17 \mathrm{~h}$ em todos os tratamentos, com e sem suplementação (Tabela 3) nos horários de maior ITGU.
Hales \& Brown (1974) reportam que a taxa de respiração basal da espécie ovina é cerca de 25 a $30 \mathrm{mov} / \mathrm{min}$, podendo subir até $300 \mathrm{mov} / \mathrm{min}$ em ovinos estressados, de acordo com Terrill \& Slee (1991). Conforme Silanikove (2000), a taxa de respiração pode quantificar a severidade do estresse pelo calor em uma frequência de 40-60, 60-80 e 80-120 mov/min, que caracteriza um estresse baixo, médio-alto e alto para ruminantes, respectivamente. Assim, ao comparar os ovinos nas dietas PA, PA + Ureia, PA + FS e PA + TA às 9 h eles obtiveram FR de 54,48; 54,30; 54,68; e 56,50 mov/min, respectivamente, as dietas superiores às recomendadas por Hales \& Brown (1974) como sendo basal para a espécie, estando no nível de estresse considerado médio-alto, segundo Silanikove (2000). Observa-se também nessas condições experimentais máxima FR às $13 \mathrm{~h}$ $39\left(\mathrm{X}_{\text {máx. }}\right)$ com 95,84 mov/min $\left(\mathrm{Y}_{\text {máx. }}\right)$ para $\mathrm{PA}+$ ureia; às 13 h 47 com 101,09 mov/min para somente PA; às $13 \mathrm{~h} 04 \mathrm{com}$ 91,09 mov/min para PA + FS; e às 13 h 35 com 107,69 mov/ min para PA + TA, podendo-se dizer que nesses horários os ovinos apresentaram-se em situação de estresse por calor alto. Esses horários estão de acordo com Cezar et al. (2004), Neiva et al. (2004) e Andrade et al. (2007), que, em situação de clima semelhante, relataram elevação da FR nos períodos da tarde, os quais concentram os maiores valores de Tar e ITGU e redução da UR, confirmando a influência do ambiente sobre o conforto térmico animal.

Ao comparar as médias da FR dos animais dentro das dietas, observa-se que os animais que consumiram PA + FS obtiveram a menor FR e os maiores valores foram encontrados no tratamento PA + TA. Fato esse justificado

Tabela 3. Valores médios dos parâmetros fisiológicos: frequência respiratória (FR), temperatura superficial (TS) e temperatura retal (TR) de ovinos mestiços de Santa Inês em cinco horários e recebendo suplementos (Sup) com diferentes fontes proteicas ureia (UR), farelo de soja (FS) e torta de algodão (TA) e somente pastagem (PA)

\begin{tabular}{|c|c|c|c|c|c|c|c|c|c|}
\hline \multirow[b]{2}{*}{$\operatorname{Dietas}^{(\mathbf{a})}$} & \multicolumn{5}{|c|}{ Horário } & \multirow{2}{*}{ Média $^{(\mathrm{c})}$} & \multirow{2}{*}{ Equações } & \multirow{2}{*}{$\mathbf{R}^{2}$} & \multirow{2}{*}{$\mathbf{C V}^{(\mathbf{b})}$} \\
\hline & 9 & 11 & 13 & 15 & 17 & & & & \\
\hline & \multicolumn{9}{|c|}{ Frequência Respiratória } \\
\hline PA & 62,75 & 78,50 & 98,00 & 108,75 & 67,75 & $83,15 \mathrm{ab}$ & $\hat{Y}=-295,3000+58,8686 h-2,1857 h^{2}$ & 0,79 & 20,26 \\
\hline PA + Uréia & 59,00 & 72,25 & 100,75 & 94,25 & 64,75 & $78,20 \mathrm{ab}$ & $\hat{Y}=-290,4150+57,6829 h-2,1536 h^{2}$ & 0,85 & 13,78 \\
\hline $\mathrm{PA}+\mathrm{FS}$ & 58,00 & 74,25 & 94,00 & 86,25 & 53,75 & $73,25 \mathrm{~b}$ & $\hat{\mathrm{Y}}=-288,83+58,2886 \mathrm{~h}-2,2357 \mathrm{~h}^{2}$ & 0,92 & 18,63 \\
\hline \multirow[t]{2}{*}{$\mathrm{PA}+\mathrm{TA}$} & 61,50 & 82,25 & 108,00 & 109,75 & 67,00 & $85,70 \mathrm{a}$ & $\hat{\mathrm{Y}}=-374,3050+72,2030 \mathrm{~h}-2,7040 \mathrm{~h}^{2}$ & 0,88 & 10,73 \\
\hline & \multicolumn{9}{|c|}{ Temperatura Superficial } \\
\hline $\mathrm{PA}$ & 35,75 & 38,75 & 38,75 & 38,00 & 33,75 & $37,00 \mathrm{~b}$ & $\hat{\mathrm{Y}}=-3,2494+6,7339 h-0,2674 \mathrm{~h}^{2}$ & 0,98 & 2,13 \\
\hline PA + Uréia & 37,50 & 39,75 & 39,25 & 38,50 & 35,00 & $38,00 \mathrm{a}$ & $\hat{\mathrm{Y}}=6,9099+5,3743 \mathrm{~h}-0,2197 \mathrm{~h}^{2}$ & 0,96 & 3,10 \\
\hline $\mathrm{PA}+\mathrm{FS}$ & 38,25 & 39,75 & 38,50 & 38,00 & 35,25 & $37,95 \mathrm{a}$ & $\hat{\mathrm{Y}}=21,7411+3,0788 \mathrm{~h}-0,1344 \mathrm{~h}^{2}$ & 0,95 & 2,32 \\
\hline \multirow[t]{2}{*}{$\mathrm{PA}+\mathrm{TA}$} & 37,75 & 38,75 & 38,75 & 38,25 & 34,25 & $37,65 \mathrm{ab}$ & $\hat{\mathrm{Y}}=14,2973+4,1396 \mathrm{~h}-0,1726 \mathrm{~h}^{2}$ & 0,98 & 3,18 \\
\hline & \multicolumn{9}{|c|}{ Temperatura Retal } \\
\hline $\mathrm{PA}$ & 39,25 & 40,00 & 40,00 & 40,00 & 40,50 & $39,95 \mathrm{a}$ & $\hat{\mathrm{Y}}=38,2530+0,1335 \mathrm{x}$ & 0,95 & 0,29 \\
\hline PA + Ureia & 39,25 & 40,00 & 40,00 & 40,00 & 40,00 & $39,85 \mathrm{a}$ & $\hat{\mathrm{Y}}=38,3751+0,1134 \mathrm{x}$ & 0,95 & 0,34 \\
\hline $\mathrm{PA}+\mathrm{FS}$ & 39,00 & 40,00 & 40,00 & 40,00 & 40,25 & $39,85 \mathrm{a}$ & $\hat{Y}=38,4436+0,1124 x$ & 0,95 & 0,45 \\
\hline $\mathrm{PA}+\mathrm{TA}$ & 39,00 & 40,00 & 40,00 & 40,00 & 40,25 & $39,85 \mathrm{a}$ & $\hat{Y}=39,84$ & - & 1,12 \\
\hline
\end{tabular}


pelo incremento calórico proporcionado pelo maior tempo de digestão proveniente do elevado teor de FDN contido na pastagem $(73,74 \%)$ associado ao suplemento com TA, que apresenta menor digestibilidade quando comparado com a ureia e o farelo de soja (Tabela 1).

Não houve significância na interação entre dietas $\mathrm{x}$ horário $(\mathrm{P}>0,05)$ para TS, TR e FR. Assim, ao analisar a TS entre as 9 e $17 \mathrm{~h}$, os ovinos obtiveram os valores máximos nos horários de $12 \mathrm{~h} 59$ com $39,15^{\circ} \mathrm{C}, 12 \mathrm{~h} 27 \mathrm{com}$ $39,88^{\circ} \mathrm{C}, 11 \mathrm{~h} 45 \operatorname{com} 39,37^{\circ} \mathrm{C}$ e $12 \mathrm{~h}$ com $39,11^{\circ} \mathrm{C}$ para as dietas PA, PA + Ureia, PA + FS e PA + TA, respectivamente. Resultados próximos aos reportados por Andrade et al. (2007) no período da tarde com ovinos mantidos no ambiente sem sombreamento.

Pode ser observada diferença $(\mathrm{p}<0,05)$ para a variável TS dentro dos grupos com diferentes dietas experimentais. Essa diferença de valores médios da TS entre os grupos com dietas (PA, PA + Ureia, PA + FS e PA + TA) pode estar mais correlacionada com a falta de padrão racial dos ovinos utilizados no presente estudo, conferindo aos grupos diferenciada tonalidade da cor do pelame dos animais. Segundo Silva et al. (2001), animais com pelame escuro, geralmente, são mais susceptíveis ao estresse por calor que os de pelame claro, por absorverem maior carga térmica radiante. Veríssimo et al. (2009), num experimento testando a tolerância ao calor em ovelhas Santa-Inês, também perceberam a elevação da temperatura das ovelhas após a exposição ao estresse por calor, em que as ovelhas de pelame claro apresentaram temperatura do pelame inferior $\left(35,9^{\circ} \mathrm{C}\right)$ às de pelame escuro $\left(36,9^{\circ} \mathrm{C}\right)$, concordando com os resultados da presente pesquisa.

Ao analisar a TR, observa-se que não houve influência dos tipos das dietas ofertadas $(\mathrm{P}>0,05)$; entretanto, percebe-se aumento linear dessa variável $(\mathrm{P}<0,05)$ nos horários 9 às $17 \mathrm{~h}$, exceto para $\mathrm{PA}+\mathrm{TA}(\mathrm{P}>0,05)$, como pode ser observado na Tabela 3. De acordo com Dukes \& Swenson (1996), a TR normal em caprinos e ovinos oscila de 38,5 a $39,5^{\circ} \mathrm{C}$, e vários fatores são capazes de causar variações normais na temperatura corporal, entre os quais a idade, $\mathrm{o}$ sexo, a estação do ano, o período do dia, o exercício e a ingestão dos alimentos. Os valores apresentados na presente pesquisa estão de acordo com Cezar et al. (2004), Neiva et al. (2004) e Andrade et al. (2007), que observaram TR dos ovinos superior no período da tarde.

Na Tabela 4, estão apresentados os valores de consumo de matéria seca total (CMST) e de forragem (CMSF), peso vivo inicial e final e o ganho em peso diário e total dos ovinos com e sem suplementação. Foram observadas diferenças $(\mathrm{P}<0,05)$ apenas para o consumo de forragem, ocorrendo efeito substitutivo da forragem pelo suplemento nos tratamentos suplementados com as diferentes fontes proteicas (ureia, FS e TA), que, por sua vez, não diferiram entre si.
O efeito de substituição do consumo da forragem pelo suplemento concentrado vem sendo observado com frequência em animais ruminantes mantidos em pastagens tropicais, com a oferta de forragem não limitante sendo maior quanto pior forem os aspectos qualitativos da planta forrageira e maiores os teores de energia dos suplementos (Voltolini et al., 2009). Assim, o efeito da substituição da forragem pelo suplemento pode ter proporcionado aos animais suplementados redução dos ciclos de pastejo e, consequentemente, reduzido o consumo de forragem. Os ovinos dos tratamentos PA, PA + ureia e PA + FS podem ter reduzido as atividades de pastejo nos horários de maior estresse; ou seja, maior Tar e ITGU explicando as menores frequências respiratórias registradas dentro desse fator. Já os animais do tratamento PA+TA sofreram maior influência do ambiente térmico, provavelmente devido à TA ser um suplemento disponibilizado mais lentamente, o que pode ter concentrado os ciclos de pastejo de maneira oposta aos demais tratamentos.

Resultados diferentes aos obtidos no presente estudo foram encontrados por Andrade et al. (2007), que avaliaram o consumo e o desempenho produtivo de ovinos mantidos em pastagens de capim Buffel recebendo doses crescentes de suplemento concentrado $(0 ; 1,0$; e 2,0\% do peso corporal) e mantidos em ambiente com sombreamentos natural e artificial e sem sombreamento. Neste estudo, Andrade et al. (2007) observaram aumento no consumo de matéria seca total e melhores desempenhos produtivos dos animais com o uso da suplementação. Além disso, os mesmos autores também não encontraram efeito de substituição da forragem pelo suplemento. Possivelmente, as condições de sombreamentos natural e artificial proporcionaram um ambiente com maior conforto térmico aos ovinos, o que pode ter estimulado o aumento no consumo de matéria seca e os melhores desempenhos apresentados pelo uso da suplementação.

A utilização de abrigos com sombreamento natural ou artificial é importante no combate do estresse térmico e, associada à suplementação, pode resultar em melhor distribuição dos ciclos de pastejo, aumentando o consumo de forragem e, consequentemente, melhorando o desempenho produtivo dos ovinos. Assim, deve ser prática a ser recomendada em sistemas de exploração de pastagens irrigadas na região Semiárida brasileira.

As suplementações, bem como as fontes proteicas nos suplementos, não afetaram $(\mathrm{P}>0,05)$ o ganho médio diário, o ganho em peso total e o peso corporal final dos ovinos; desse modo, o uso exclusivo da pastagem mostrou-se mais vantajoso economicamente, eliminando os custos com suplementação sem interferir no desempenho animal.

Segundo Carvalho et al. (2006), a condição para adoção da suplementação nos sistemas de produção de carne é que ela atenda a uma relação custo/benefício favorá- 
Tabela 4. Consumo de matéria seca total (CMST), consumo de matéria seca de forragem (CMSF), peso vivo inicial (PVI), peso vivo final (PVF) e ganho médio diário (GMD) de ovinos mantidos somente em pastagem de Tifton 85 (PA) e pastagem com suplementação proteica com fonte de ureia (PA + ureia), farelo de soja (PA + FS) e torta de algodão (PA + TA)

\begin{tabular}{lcccccc}
\hline \multirow{2}{*}{ Variáveis } & \multicolumn{7}{c}{ Tratamentos } \\
\cline { 2 - 7 } & PA & PA+uréia & PA+FS & PA+TA & EPM $^{(\text {a) }}$ & P $^{(\mathbf{b})}$ \\
\hline PVI (kg) & 28,30 & 28,56 & 28,30 & 28,17 & 1,09 & 0,99 \\
PVF (kg) & 35,60 & 33,57 & 36,67 & 36,12 & 1,31 & 0,38 \\
CMST (kg/animal/dia) & 628,50 & 571,47 & 623,16 & 592,89 & 37,82 & 0,64 \\
CMSF (kg/animal/dia) & $628,50 \mathrm{a}$ & $435,90 \mathrm{~b}$ & $401,80 \mathrm{~b}$ & $412,80 \mathrm{~b}$ & 42,89 & 0,01 \\
GMD (g) & 87,00 & 60,00 & 100,00 & 95,00 & 0,015 & 0,27 \\
GPT (kg) & 7,30 & 5,01 & 8,37 & 7,96 & 1,27 & 0,27 \\
\hline
\end{tabular}

${ }^{(a)}$ EPM $=$ Erro-padrão da média ${ }^{\text {(b) }} \mathrm{P}=$ Probabilidade ${ }^{(\mathrm{c})}$ Médias seguidas pela mesma letra na linha não diferem estatisticamente pelo teste de Tukey $(\mathrm{P}<0,05)$.

vel, podendo ocorrer situações em que determinada suplementação não, necessariamente, pague o seu custo, e nesse caso a análise deve ser feita dentro de todo o sistema de produção de carne, considerando vantagens diretas e indiretas da suplementação dos animais.

O ganho em peso diário dos ovinos apresentado no presente trabalho de 0,06 a $0,100 \mathrm{~kg} / \mathrm{animal} /$ dia está próximo aos encontrados por Neiva et al. (2004), que ofereceram baixo teor de ração concentrada para ovinos Santa Inês confinados e em ambiente sem sombreamento; entretanto, quando mantidos no ambiente sombreado os ovinos apresentaram elevação do GMD de 64 g/animal/ dia no ambiente sem sombreamento para $180 \mathrm{~g} / \mathrm{animal} / \mathrm{dia}$ no ambiente sombreado. Os valores de GMD também são inferiores aos reportados por Barros et al. (2005) e Andrade et al. (2007), que avaliaram diferentes doses de suplemento concentrado para a terminação ovinos mantidos em pastagem no sertão paraibano. Esses autores observaram ganhos médios diários que variaram de 144,3 a 234 gramas/animal/dia e de 100 a 200 gramas/animal/dia, respectivamente, durante o período de avaliação.

Assim, a suplementação como ferramenta para aumentar a produção em sistemas de produção de ovinos em pastagens tropicais deve ser utilizada a partir da observação de critérios como idade, peso, potencial genético dos animais, doses suplementares a serem ofertadas e conforto térmico animal, de forma a estabelecer as melhores respostas em desempenho e qualidade do produto final.

\section{CONCLUSÕES}

Em condições climáticas impostas pelo experimento, o turno da tarde conduziu os animais, independentemente da dieta, a uma condição de elevado estresse por calor. A suplementação influenciou o consumo de matéria seca de forragem sem alterar o desempenho dos ovinos, sendo economicamente inviável. A fonte proteica obtida a partir da torta de algodão e utilizada no suplemento para ovinos em pastejo elevou a sua FR, influenciando no seu conforto térmico.

\section{REFERÊNCIAS}

Andrade IS, Souza BB, Pereira Filho JM \& Silva AMA (2007) Parâmetros fisiológicos e desempenho de ovinos santa inês submetidos a diferentes tipos de sombreamento e a suplementação em pastejo. Ciência e Agrotecnologia, 31:540-547.

Baêta FC \& Souza CF (1997) Ambiência em edificações rurais conforto animal. Viçosa, UFV, 246p.

Barros NN, Vasconcelos VR de, Wander AE \& Araujo MRA de (2005) Eficiência bioeconômica de cordeiros $F_{1}$ Dorper x Santa Inês para produção de carne. Pesquisa Agropecuária Brasileira, 40:825-831.

Buffington DE, Colazzo-Arocho A \& Caton GH (1981) Black globe humidity comfort index (BGHI) as comfort equation for dairy cows. Transaction of the ASAE, 24:711-714.

Campos JHBC, Silva VPR da, Azevedo P V, Borges C JR, Soares J M, Moura MSB \& Silva BB (2008) Evapotranspiração e produtividade da mangueira sob diferentes tratamentos de irrigação. Revista Brasileira de Engenharia Agrícola e Ambiental, 12:150156.

Carvalho S, Vergueiro A, Kieling R, Teixeira RC, Pivato J, Viero R \& Cruz AN (2006) Desempenho e características da carcaça de cordeiros mantidos em pastagem de Tifton-85 e suplementados com diferentes níveis de concentrado. Revista Brasileira de Agrociência, 12:357-361.

Cezar M F, Souza BB de, Souza WH de, Pimenta Filho EC, Tavares GP \& Medeiros GX (2004) Avaliação de parâmetros fisiológicos de ovinos dorper, santa inês e seus mestiços perante condições climáticas do trópico semi-árido nordestino. Ciência e Agrotecnologia, 28:614-620.

Dukes HH \& Swenson M J (1996) Fisiologia dos animais domésticos. 10.ed. Rio de Janeiro, Guanabara Koogan, 199-205p.

Fagundes JL, Fonseca DM da, Gomide JA, Nascimento Jr., D do; Victor CMT, Morais RV de, Mistura C, Reis GC \& Martuscello JA (2005) Acúmulo de forragem em pastos de Brachiaria decumbens adubados com nitrogênio. Pesquisa Agropecuária Brasileira, 40:397-403.

Hales J R S \& Brown GD (1974) Net energetic and thermoregulatory efficiency during panting in the sheep. Comparative Biochemical Physiology, 49:413-422. [S.1.].

IBGE - Fundação Instituto Brasileiro de Geografia e Estatísticas (2009) Sistema IBGE de Recuperação Automática. Disponível em: <http://www.sidra.ibge.gov.br/>. Acessado em: 14 de abril de 2009.

Machado A \& Conceição AR (2002) Programa estatístico WinStat sistema de análise estatística para Windows. Pelotas, UFPEL. Versão 2.0. 
Martinez JC (2004) Substituição do milho moído fino por polpa cítrica peletizada no concentrado de vacas leiteiras mantidas em pastagens de Capim Elefante durante o outono-inverno. Dissertação de Mestrado. Escola Superior de Agricultura "Luiz de Queiroz”, Piracicaba. 122p.

Molento MB, Tasca C, Ferreira M, Bononi R \& Stecca E (2004) Método Famacha como parâmetro clínico individual de infecção por 'Haemonchus contortus' em pequenos ruminantes. Ciência Rural, 34:1139-1145.

Moreira JN, Voltolini TV, Moura Neto JB, Santos RD, França CA \& Araújo GGL (2008) Alternativas de volumosos para caprinos em crescimento. Revista Brasileira de Saúde e Produção Animal, 9:407-415.

National Research Coucil - NRC (2007) Nutrient requeriments of small ruminants. $7^{\text {th }}$ d. Washington, National Academic Press. 408p.

Neiva JNM, Teixeira M, Turco SHN, Oliveira SMP \& Moura AAAN (2004) Efeito do estresse climático sobre os parâmetros produtivos e fisiológicos de ovinos Santa Inês mantidos em confinamento na região litorânea do Nordeste do Brasil. Revista Brasileira de Zootecnia, 33:668-678.

Oliveira FMM, Dantas RT, Furtado DA, Nascimento JWB \& Medeiros NA (2005) Parâmetros de conforto térmico e fisiológico de ovinos Santa Inês, sob diferentes sistemas de acondicionamento. Revista Brasileira de Engenharia Agrícola e Ambiental, 9:631-635.

Santos FCB, Souza BB de, Alfaro CEP, Cezar MF, Pimenta Filho EC, Acosta AAA \& Santos JRS dos (2005) Adaptabilidade de caprinos exóticos e naturalizados ao clima semi-árido do nordeste brasileiro. Ciência e Agrotécnologia, 29:142-149.

Silanikove N (2000) Effects of heat stress on the welfare of extensively managed domestic ruminants. Livestock Production Science, 67:1-18. [S.1.].
Silva DJ \& Queiroz AC (2002) Análise de alimentos: métodos químicos e bioquímicos. 3.ed. Viçosa, UFV. 235p.

Silva RG, La Scala Jr N \& Pocay PLB (2001) Transmissão de radiação ultravioleta através do pelame e da epiderme de bovinos. Revista Brasileira de Zootecnia, 30:1939-1947.

Souza BB de, Silva RMN da, Marinho ML, Silva GA, Silva EMN da \& Souza AP de (2007) Parâmetros fisiológicos e índice de tolerância ao calor de bovinos da raça Sindi no Semi-árido paraibano. Ciência e Agrotecnologia, 31:883-888.

Souza DE, Souza BB, Souza WH, Cezar MF, Santos JRS \& Tavares GP (2005) Determinação dos parâmetros fisiológicos e gradiente térmico de diferentes grupos genéticos de caprinos no semiárido. Ciência e Agrotécnologia, 29:177-184.

Starling JMC, Silva RG, Cerón-Muñoz M, Barbosa GSSC \& Costa MJRP (2002) Análise de algumas variáveis fisiológicas para avaliação do grau de adaptação de ovinos submetidos ao estresse por calor. Revista Brasileira de Zootecnia, 31:2070-2077.

Terrill CE \& Slee J (1991) Breed differences in adaptation of sheep. In: Maijala K (Ed.) Genetic resources of pigs, sheep and goat. Amsterdam, Elsevier. 195-233p.

Veríssimo CJ, Titto CG, Katiki LM, Bueno MS, Cunha EA, Mourão GB, Otsuk IP, Pereira AMF, Nogueira Filho JCM \& Titto EAL (2009) Tolerância ao calor em ovelhas Santa Inês de pelagem clara e escura. Revista Brasileira de Saúde e Produção Animal, 10:159-167.

Voltolini TV, Moreira JN, Nogueira DM, Pereira LGR, Azevedo SRB de \& Lins PRC (2009) Fontes protéicas no suplemento concentrado de ovinos em pastejo. Acta Scientiarum, 1:1-10. 